\title{
Estética e informação em um vídeo de violência policial na periferia ${ }^{1}$
}

\section{Aesthetics and information on a video of police violence in the suburbs}

Felipe Polydoro 2

1 A primeira versão deste texto foi apresentada no seminário Polarizações, promovido pelo Grupo de Pesquisa Mídia e Narrativa, da Pontifícia Universidade Católica de Minas Gerais (PUC Minas), em Belo Horizonte, de 3-5 de novembro de 2015 
Neste artigo, analisamos detidamente um vídeo amador que documenta um episódio de violência policial em uma favela carioca, um entre tantos exemplos de registros amadores contemporâneos a revelar casos de abusos policiais nas periferias brasileiras. Este tem como traço singular o fato de que a vítima é o próprio cinegrafista. Nesta análise, tomamos como base um modo de observação exposto por Didi-Huberman (2012), que interliga aspectos documentais e estéticos na análise de imagens captadas em condições extremas, numa aproximação que enfatiza seu estatuto de acontecimento.

\section{Palavras-chave}

Vídeo amador, política das imagens, análise da imagem. 


\section{Abstract}

In this paper, we analyze an amateur video that records a case of police violence in a slum ["favela"] located in Rio de Janeiro. It's one of many examples of contemporary amateur recordings that reveal abuses committed by policemen in Brazilian suburbs. This one has one singular detail: the victim of the violence is the cameraman. We use a method of analysis developed by Didi-Huberman (2012), which connects aesthetics and documentary aspects to observe images shot in extreme conditions, an approach that emphasizes its status of event.

\section{Keywords}

Amateur video, politics of image, image analysis. 
Quatro rapazes conversam em clima descontraído. Um deles registra a brincadeira na câmera de celular. É noite, está escuro, vê-se aquilo que o flash da câmera ilumina: os corpos dos garotos saturados pela luz, um aparece de cada vez, todos próximos da câmera. Estão na rua, mas quase não se enxerga o fundo. Pontos de iluminação pública dão alguma profundidade ao campo. A câmera não se limita a documentar a diversão. Ao criar uma cena, o dispositivo também medeia e agencia a brincadeira. É ciente da câmera, mas sem olhar para ela, que um dos garotos conta uma piada para os outros dois situados fora de campo. Solicita ao operador que os enquadre. O que ele faz é desempenhar uma singela encenação para a tela. O cinegrafista aproxima a câmera de um, de outro, quase encosta a lente no garoto que conta a piada, toca seu pescoço com a mão (esta é uma das duas vezes em que algum fragmento do corpo do operador aparecerá na tela; mais adiante, veremos um vislumbre do pé). Os rapazes são negros e o cenário sugere que a cena desenrola-se numa periferia. Na verdade, dificilmente algum espectador irá assistir a este vídeo ${ }^{3}$ sem saber que se passa na favela da Palmeirinha, no Rio de Janeiro, e que o cinegrafista adolescente, Alan de Souza Lima, será baleado e morto durante a filmagem. Estas informações constam no título da página que exibe o vídeo no YouTube e também o acompanham uma vez compartilhado em redes sociais como Facebook ou Twitter.

Trata-se de um entre tantos exemplos de registros amadores contemporâneos a revelar casos de violência policial nas periferias brasileiras, episódios que só ganham visibilidade nas mídias na medida em que são documentados na forma de vídeo e distribuídos nos meios digitais. São imagens da alçada de não-profissionais a enfrentar a anestesia da mídia tradicional (CAPRIGLIONE, 2015) diante dos abusos contra populações de periferia. "A invisibilidade da realidade da periferia é parte do mecanismo que permite a supressão de direitos. Só reivindica direitos quem é visível no campo do debate democrático" (CAPRIGLIONE, 2015, p. 57).

Dessa forma, conseguem adentrar o espaço público e incitam um debate invariavelmente polarizado entre apoiadores da polícia e defensores de direitos humanos. Além disso, esses flagrantes audiovisuais que evidenciam abusos por parte de policiais têm a capacidade de interferir no desfecho de casos específicos, sobretudo quando há a tentativa de forjar tiroteios ou "plantar" armas nas vítimas. No flagrante da Favela da Palmeirinha, os rapazes foram acusados de trocar tiros com a polícia. Um deles foi preso. O vídeo mostra que, no instante dos disparos, os rapazes apenas conversavam entre si. Esta conversa amistosa é interrompida e atravessada por tiros que irrompem abruptamente. Não vemos os policiais chegando, nem as armas no momento dos disparos. 
Ouvimos os tiros, mas, em termos visuais, percebemos, na imagem, apenas os efeitos dos tiros que atingem o rapaz que segura o celular-câmera. O aparelho desaba e a câmera segue ligada, estática, por mais sete minutos e meio, quando grava sobretudo o som das ocorrências situadas fora de campo. Embora não dê a ver diretamente os fatos registrados, o vídeo revelou o suficiente para provar a inocência dos rapazes e desencadear um processo contra os policiais envolvidos processo ainda sem um desfecho.

Neste artigo, produzimos uma análise deste vídeo de evidência cujas ocorrências trágicas não estão transparecidas na dimensão visível. Tomando como base o modo de observação exposto por Didi-Huberman no livro Imagens apesar de tudo (2012), interligamos os aspectos documentais aos estéticos, de maneira a tirar todas as consequências de se abordar imagens captadas em condições extremas, numa abordagem que enfatiza seu estatuto de acontecimento.

\section{Uma imagem atravessada pelo acontecimento}

Comecemos analisando a imagem mais demoradamente. Embora fruto de uma única tomada, este longo plano parece dotado de montagem: temos pelo menos três momentos distintos separados por modificações substanciais na imagem; uma montagem interna. Na primeira parte, com duração de 1 min14seg, é quando efetivamente vemos as ações desempenhadas pelo corpos e objetos filmados. Aqui os quatro rapazes brincam em posições relativamente fixas. A amplitude da cena está delimitada pelos corpos - um deles à direita, os outros dois à esquerda do operador. Este permanece fixo, apenas a câmera se mexe.

A câmera se desloca sobretudo em duas direções: lateralmente, variando o rapaz enquadrado e estabelecendo algo como uma linha de diálogo; e na profundidade, aproximando-se e afastando-se de cada um deles (por vezes, quase os toca). Traz a instabilidade típica do registro audiovisual amador com a câmera na mão, um movimento que pode ser definido como a síntese da ação estratégica da filmagem com o balançar espontâneo da mão, braço e corpo. Este trecho é todo proximidade. Aliás, o vídeo como um todo caracteriza-se por uma imagem de feição bidimensional e por um encaixotamento claustrofóbico, efeito agravado pela materialidade pixelada e pelas duas faixas escuras verticais que emolduram a imagem, como é típico na reprodução de vídeos de celular. Impossível não pensar na correspondência entre a organização espacial interna a esse objeto audiovisual e a "arquitetura" da favela.

Os planos variam entre primeiro plano e plano americano. No entanto, mesmo quando a câmera distancia-se ligeiramente dos rapazes, o reflexo da luminosidade acentuada do flash em contraste com o fundo escuro elimina a profundidade. 
Há recorrência de um movimento de câmera em direção aos rapazes, como se esta fosse atingi-los. A câmara é um personagem e um agente: não se trata de um olho situado a certa distância que contempla e registra a cena, a descrever uma ocorrência tal como vê. Agencia os diálogos, faz falar, intervém, realiza uma mediação. Está posicionada - literalmente - em meio à conversa.

Ao mesmo tempo em que agencia o clima amistoso, a câmera impõe-se de modo agressivo: a luz forte satura os corpos e incomoda o olho; uma vez enquadrados, a primeira reação de cada rapaz é tapar o rosto. A relação com o espaço aqui é de um certo aprisionamento, apesar da câmera solta. Todo o tempo, o enquadramento capta apenas um pedaço da ação: os personagens estão sempre dirigindo a voz e o olhar para alguém fora de campo; ouvimos permanentemente falas e ruídos sem enxergar a fonte.

Quando a câmera se desloca para fora do espaço descrito acima é como se houvesse um corte na montagem interna e se iniciasse um novo plano, o segundo momento do vídeo, curtíssimo mas fundamental: é aqui que se impõe o choque e a ruptura. São poucos segundos de abstração visual e marcações sonoras que indicam movimento. Pontos luminosos desenham riscos na tela, na forma de raios. São os dados sonoros que permitem distinguir o que ocorre: o barulho dos passos e do vento chocando-se contra o gravador, combinado com o sobe e desce no enquadramento e os raios de luzes, anunciam que o rapaz está correndo.

Instantes depois dos estampidos, essa sucessão abstrata de luzes é interrompida e vemos com nitidez um pedaço da bicicleta na imagem. Imediatamente depois disso, indicando o fim do movimento da queda (e só então pode-se atestar que o movimento de cores e luzes registrava a queda do operador), percebemos um punhado de terra ser lançado contra a câmera - um punhado de terra vindo do chão, efeito da bicicleta pesada estatelando-se. Logo em seguida ao choque, a imagem obscurece - o flash parece apagar por um momento. Vemos uma silhueta da imagem que virá a seguir. O flash gradativamente restabelece-se e fixa-se, assim, o quadro imóvel que persistirá até o fim.

Já marcado por uma textura que remete ao tátil, por um efeito geral de proximidade física e ausência de profundidade - e uma disposição dos elementos que afunila o espaço, efeito agravado nos instantes de indefinição visual, dada a qualidade bidimensional da imagem abstrata - o vídeo registra, literalmente, um choque com a matéria do mundo. A matéria que se desprende do chão colide com a matéria do dispositivo, que deixa o rastro indicial de um impacto físico da câmera com a matéria sólida do chão, câmera aqui situada no interior do acontecimento, no sentido mais literal possível. Uma alusão às condições desta captação direta, nas quais o equipamento é tão atravessado por contingências e 
causas da ordem do mundo, está tão à mercê de ações e de vontades externas à cena e ao conhecimento quanto os sujeitos que terminarão baleados. O celular - e o adolescente que o carrega - encontra-se envolto no acontecimento, entranhado fisicamente, e não sobra a distância espacial da visão. Fatos como a chegada dos policiais e os disparos permanecem fora de campo - e estavam, tudo indica, no exterior do campo de visão do adolescente que filmava. Ora, o efeito da câmera subjetiva é de coincidência entre imagem e olhar do operador, que se posiciona como um personagem.

A característica estrutural marcante deste vídeo é a ruptura e o desvio; o fluxo irrelevante do cotidiano interrompido por uma intervenção violenta alheia à vontade e até mesmo ao conhecimento do sujeito que filma. Há um fato a atravessar a filmagem em andamento; fato cujos pormenores não guardam qualquer relação com os propósitos da filmagem explicitados na própria imagem. Esse sentido de intrusão encontra-se potencializado pela primazia do som nesses instantes de ruptura. Os procedimentos em torno do ato de olhar admitem um certo controle (inclusive a possibilidade física de fechar os olhos) inexistente no ato de ouvir. Chion explicita essa diferença no caso da recepção de um produto audiovisual:

No cinema, o olhar é uma exploração, simultaneamente temporal e espacial, num dado a ver delimitado que se mantém no quadro de um ecrã. Ao passo que a escuta é uma exploração num dado a ouvir e até num imposto a ouvir muito menos delimitado em todos os aspectos, com contornos incertos e mutáveis. [...] Este imposto a ouvir é tal que, nele, dificilmente podemos excluir, selecionar e distinguir seja o que for. No som, há sempre qualquer coisa que nos submerge e nos surpreende façamos o que fizermos. [...] Na situação cultural atual, o som, mais facilmente do que a imagem, tem o poder de a saturar $\mathrm{e}$ de a curto-circuitar (CHION, 2008, p. 32-33).

A imposição de um ouvir que nos submerge e nos surpreende e tem o poder de saturar e curto-circuitar a imagem: isso soa como uma descrição precisa do vídeo que analisamos. Um segundo após a estabilização da imagem, ouvimos o som do cinegrafista atingido - o ponto mais pungente e desconcertante deste vídeo, o mais próximo da definição do efeito traumático, conforme Barthes (1990, p. 24): "o que interrompe a linguagem e bloqueia a significação". Barthes se refere à fotografia jornalística - "incêndios, naufrágios, catástrofes, mortes violentas, tomadas 'ao vivo' [...] foto-choque [...] de que nada se tem a dizer" (p. 24) - circunstância na qual a suspensão de sentido decorre da visão de uma imagem que fixa um instante 
de horror. Aqui, porém, não temos nem a predominância do sentido da visão - mas da audição - nem uma imagem fixa: mas um objeto audiovisual em movimento. O efeito traumático provocado pelo som só se concretiza uma vez percebido como resultado dos choques imediatamente anteriores: os tiros, o movimento de queda.

Ouve-se em seguida, um pouco mais distante do microfone, os lamentos do outro rapaz ferido. Este reza e formula frases com nexo e sentido. Uma vez que não há a exposição visual da violência - ferimentos, sangue - os únicos elementos a remeter mais diretamente ao corpo ferido são os sons agónicos dos rapazes. Mais adiante, ouvimos outros personagens referirem-se aos feridos, sobretudo ao adolescente morto.

Este trecho de lamentos simultâneos dura cerca de 40 segundos e, a partir do momento em que o vídeo completa dois minutos, não ouvimos mais Alan. Deste momento em diante - e o vídeo dura mais sete minutos e meio - deduzse que o adolescente já morreu, embora o dispositivo permaneça ligado. Como o desfecho do jovem já vem informado no título do vídeo, neste instante, qualquer espectador está informado sobre a morte. Isto é: não se trata mais de uma câmera subjetiva do ponto de vista do cinegrafista. O dispositivo opera enquanto um ente autônomo. O celular, sua operação, suas imagens, sobrevivem. Aconteceu atrás da câmera algum tipo de passagem, que nas imagens está inscrita de duas formas: tanto os movimentos bruscos e abstratos que dominam o plano logo após os tiros quanto o quadro fixo com um fragmento de bicicleta indicam uma circunstância de captação na qual a filmagem deixa de ser operada pelo cinegrafista, no sentido estrito, e o dispositivo adquire autonomia (também no sentido estrito, ignorando por ora o traço autônomo da feitura de qualquer imagem técnica).

Há um núcleo aqui, o cerne deste corte abrupto, que dura dez segundos, desde o primeiro tiro até o momento em que a imagem se estabiliza novamente, com a bicicleta no chão, iluminada pelo flash. Localiza-se aqui essa passagem no estatuto da imagem: de um registro cotidiano insubstancial a um acontecimento dotado de relevância e singularidade. Alteração significativa também no nível da enunciação: do cinegrafista amador à câmera autônoma. A câmera do celular, este aparelho de uso pessoal, um dispositivo de subjetividade central na contemporaneidade.

O ponto de vista da câmera é o de alguém deitado, imóvel, muito próximo da bicicleta caída. Trata-se de um enquadramento incomum, estranho: o fragmento da roda da bicicleta está no topo, encostado em uma superfície sólida que parece ser o chão. A captação dá-se, tudo indica, de cabeça para baixo. O paradoxo: ainda que seja simples deduzir a autonomia do dispositivo a partir de determinado momento, persiste um efeito de câmera subjetiva. Continuamos sentindo a presença do operador atrás da câmera; um corpo baleado, imóvel, mas ainda 
presente. E este registro audiovisual faz diversas alusões à presença deste corpo. Primeiro, ouvimos o horror de sua agonia. Depois, as falas captadas pelo microfone mencionam diversas vezes o "menino" caído. O "corpo" da bicicleta enquadrado em primeiríssimo plano é índice do evento traumático.

Nos cerca de sete minutos e meio restantes, terceira parte da montagem interna, os dados sonoros propiciam algo como a visualização mental da cena gravada. Os diversos sons ao fundo, sincrônicos, com variadas distâncias do microfone, produzem um efeito de tridimensionalidade. Curiosamente, a sensação de alargamento do espaço é maior na audição do que na visão; identificamos emissões vocais de variadas distâncias. Demanda um certo esforço a construção coerente das ocorrências exclusivamente por meio do som e, assim, a organização de uma narrativa que dá seguimento aos fatos anteriores. As falas são desencontradas, sobrepõem-se umas às outras. Por vezes, certos trechos são inaudíveis. De outra parte, há conversas que oferecem sentido e compreensão de alguns detalhes em torno das ocorrências chocantes.

A já mencionada fala do outro rapaz ferido, Chauan, continuará ao longo de todo o vídeo. Suas falas soam nítidas: ele está próximo do equipamento. Em um primeiro momento, Chauan reza. É uma oração cujo discurso dirige-se diretamente a Deus: ele pede ao Senhor que não o abandone, que perdoe seus pecados, que o ajude, pois é evangélico. Em certo momento, no meio da reza, ele chora. Pede ajuda a outro dos rapazes, Lobão. "Me ajuda, Lobão, por favor. Eu levei um tiro. Não me deixa morrer. Me ajuda, Lobão". O amigo responde, lacônico, intimidado: "Calma, fica quietinho". Chauan pede ajuda aos policiais, que na hora não respondem. Mais tarde o colocarão no carro. Não é difícil identificar as falas dos policiais: soam seguras, frias e autoritárias. Na maior parte das vezes, são vozes de comando, no imperativo. Ouvimos algumas declarações esparsas referindo-se aos tiros contra os rapazes inocentes. Sobre isso, há três momentos-chave. Um pouco depois de a imagem se estabilizar, um policial pergunta para os rapazes: "Vocês correram por quê?". O ferido responde: "A gente estava brincando, senhor". Alguns minutos depois, num instante de sobreposição de vozes, ouve-se um morador lamentar que os rapazes "são trabalhadores". Uma voz autoritária então o interpela: "Cidadão, ô cidadão, presta a atenção... Entraram no meio da troca de tiro aqui com a gente". Só aparece uma menção explícita ao adolescente morto depois dos seis minutos. Uma mulher grita: "Está morto este menino, gente?". E depois: "Alguém conhece este menino?" Outro morador responde: "Não é o filho do coisa?". A mesma mulher: "Chama a mãe dele aqui, gente! Chama a mãe dele pelo menos". Neste momento há muitas falas sobrepostas, além do ruído constante de um carro. Ouve-se o fragmento de uma frase do policial: "é desconhecido" (aparentemente, ninguém conhece o menino). Tudo indica que este é o momento em que retiram o corpo do rapaz. 
Todo este terceiro trecho que concilia um quadro estático na dimensão visual com dados sonoros dá-se após a eclosão dos tiros e, consequentemente, de uma crise na narrativa, com uma redefinição dos possíveis e o suspense em torno tanto das consequências vindouras quanto da compreensão do fato recém ocorrido. Desta forma, a enunciação mobiliza um tipo de atenção concentrada em dados aptos a completar a narrativa, a responder a um estado que convoca algum tipo de decisão. Qualquer narrativa audiovisual caracterizada por choque seguido de suspense já constitui uma estratégia eficaz de mobilização da atenção do espectador. Neste caso, à incerteza quanto ao desenlace soma-se uma incerteza semiótica: ainda que as linhas gerais do ocorrido já estejam anunciadas, há dificuldade de se associar os signos visuais e sonoros a fatos específicos no mundo histórico. A vontade de saber aqui diz respeito tanto ao suspense sobre o ocorrido e o vir a ser, quanto à decifração do significado dos dados aos sentidos.

\section{Articulação entre os regimes estético e documental}

As particularidades de ordem estética analisadas aqui, aptas a produzir uma série de efeitos (alguns dos quais já descritos), em certo sentido obtidas de modo acidental, possuem também uma dimensão documental. Isto é: os detalhes formais dizem, também eles, algo sobre o fato registrado. Por isso, analisá-las não significa recair em formalismo, simplesmente estetizar uma tragédia. Detalhes obscuros e abstratos, bem observados, oferecem informações substanciais sobre o acontecimento.

Em seu livro de enfoque historiográfico que aborda documentos visuais do Holocausto, Didi-Huberman (2012) vale-se de um método de articulação entre os regimes documental-histórico e estético da imagem valioso para nossa análise. Além disso, ao analisar quatro fotografias de Auschwitz captadas em 1944 por um membro do Sonderkommando ${ }^{4}$, sublinha o estatuto de acontecimento dessas imagens. Tomadas secretamente de dentro da câmera de gás e da área imediatamente em frente, as fotografias trazem sinais que remetem ao procedimento extremo de produção, que envolvia o risco de vida do operador. Duas dessas imagens, que mostram, a uma certa distância, corpos deitados sendo incinerados à luz do dia, exibem algo como uma moldura preta: de fato, a "moldura" nada mais é do que o interior da câmera de gás e o quadro, a janela através da qual é possível visualizar a cena terrível.

4 O Sonderkommando (literalmente, "comando especial") era um grupo constituído predominantemente por prisioneiros judeus que tinha por função executar alguns trabalhos braçais envolvendo o extermínio em massa nos campos de concentração nazista. Respondia por tarefas tais como: carregar os corpos das câmeras de gás até os locais de cremação, operar os fornos, limpar as câmeras, entre outros. 
As outras duas fotografias dão a ver um grupo de mulheres nuas prestes a adentrar a câmera de gás. Essas são ainda mais obscuras: numa, cujos referentes encontram-se em orientação transversal, vemos as mulheres bem pequenas, distantes, no canto inferior direito. A outra, que capta a mesma cena, é praticamente um borrão. Distinguimos apenas algumas árvores no canto superior. Didi-Huberman (2012) critica os historiadores que interferiram nestas imagens, limpando as áreas escuras, reenquadrando e aproximando dos trechos nos quais a informação visual encontra-se mais nítida.

Ao reenquadrar estas fotografias, comete-se uma manipulação simultaneamente formal, histórica, ética e ontológica. A massa negra que envolve a visão dos cadáveres e das fossas, essa massa onde nada é visível, dá, na realidade, uma massa visual tão preciosa quanto o resto da superfície impressionada. Esta massa onde nada é visível é o espaço da câmera de gás: a câmera obscura onde alguém teve de se retirar para trazer à luz o trabalho do Sonderkommando, lá fora, nas fossas de incineração. Essa massa negra dá-nos a ver a própria situação, o espaço de possibilidade, a condição de existência dessas fotografias. [...] Ao reenquadrar estas imagens, quis-se sem dúvida preservar o documento (o resultado visível, a informação distinta). Mas suprimiu-se a sua fenomenologia, tudo aquilo que fazia destas imagens um acontecimento. Essa massa negra é a própria marca do estatuto último a partir do qual estas imagens devem ser compreendidas: o seu estatuto de acontecimento visual (DIDI-HUBERMAN, 2012, p. 56).

Imagens-acontecimento não apenas porque captam e documentam um fragmento das atrocidades de Auschwitz, episódio central na história recente da Europa, cujo horror testa os limites da representação; mas também porque transportam as condições extremas de sua criação. Esse trânsito dá-se sobretudo por meio de marcas presentes na própria imagem, marcas de cunho formal que, numa oposição esquemática entre forma e conteúdo, poderiam ser definidas como puramente estéticas e que, numa visada documental mais fechada, parecem sujeira e ruído. Todavia, aqui remetem aos pormenores da captura das imagens, ao fato do encontro entre máquina e mundo que, fruto de uma experiência limite, constitui um acontecimento. Didi-Huberman recomenda interrogar até mesmo "a função formal de uma zona em que 'não se vê nada', como se costuma dizer, erradamente, diante de algo que parece destituído de valor informativo, um quadro de sombra, por exemplo" (DIDI-HUBERMAN, 2012, p. 61). 
Aplicando este modo de olhar ao vídeo de Palmeirinha analisado aqui: a composição visualmente confusa nos momentos dos disparos, que indica movimento, informa que os disparos foram provenientes de fora do campo de visão do cinegrafista, que, aparentemente, desconhecia a presença dos policiais. A duração longa do vídeo com a câmera fixa indica a demora para acudir os feridos. O tom de voz controlado dos moradores e dos rapazes e a relativa estabilidade da cena acústica revelam o respeito temeroso com policiais que, ali mesmo, já tentavam incriminar injustamente os rapazes ("Eles entraram no meio da troca de tiro aqui com a gente", disse um policial).

Percebe-se um único grito de indignação e revolta, de longe, logo depois dos tiros: uma mulher vocifera palavrões, um protesto agressivo que contrasta com as falas temerosas posteriores. O fato de o vídeo não enquadrar em nenhum momento os policiais - resultado do caráter acidental da filmagem - acaba coerente com a postura amedrontada, de falas com orientação tangencial, jamais dirigidas diretamente aos policiais. Quando um morador enuncia: "Eram trabalhadores", parece um lamento dito a esmo, e não uma cobrança. A câmera também não os confronta, os enquadra frontalmente. Os rostos dos policiais vão aparecer nitidamente só em outro vídeo, gravado pela câmera interna da viatura e que capta um deles disparando uma espingarda.

É comum em outros vídeos amadores que flagram abusos policiais o resguardo por parte dos cinegrafistas. Frequentemente, nota-se que os policiais não têm ciência da filmagem e que o operador posiciona-se à distância. Essa distância, fundamental para a denúncia mas geralmente também sinônimo da impotência para intervir diretamente no fato, é a inscrição no objeto audiovisual da relação entre o cinegrafista intimidado e a polícia. No final de setembro de 2015, veio a público um vídeo 5 nesse molde, gravado no Morro da Providência, no Rio de Janeiro. Ao lado do corpo já morto do adolescente Eduardo Felipe Santos Victor, policiais tentam forjar uma cena de tiroteio. Envolvem a arma com a mão do rapaz e atiram para o alto. O vídeo flagra o fato momentos depois de o rapaz ser alvejado. O corpo já se encontra caído, ensanguentado, e os policiais agora dedicam-se ao engodo.

A filmagem é captada do alto, em um ponto distante o suficiente para que a cinegrafista não seja percebida pelos policiais. Enquanto filma, ela conversa com outras duas pessoas, uma mulher e um homem, sobre o risco que correm em captar a cena. Fala baixo, diz que não vai mostrar o rosto na imagem, alude à necessidade de cautela. Em seguida afirma, em tom confiante e altivo, que vai continuar filmando, que "não vai sair daqui não", pois os policiais "estão deixando o moleque morrer". 
No espaço inferior da imagem, percebe-se um parapeito branco, uma das marcas a apontar para a condição arriscada de captura da imagem. O parapeito é um anteparo real atrás do qual a cinegrafista se esconde para filmar. Na imagem, é o que indica sua posição oculta e, consequentemente, a condição de câmera escondida a vigiar um grupo de policiais cuja ação falseadora só prossegue em virtude do desconhecimento da filmagem. Os quatro policiais e o corpo de Eduardo situam-se na parte de trás de uma casa, numa posição por si só já oculta. Enquanto um deles descarrega a arma, tomando o cuidado de acomodá-la na mão do rapaz morto, os outros policiais observam em volta e certificam-se de que ninguém os enxerga.

A cinegrafista menciona pelo menos duas vezes o incômodo físico de filmar, indicando uma posição não-usual da câmera. Diz que "o braço está doendo, mas vou continuar filmando". Provavelmente, o braço está esticado e o celular-câmera distante do olho. A imagem treme todo o tempo, também marcando o esforço físico subjacente à filmagem.

No vídeo de Palmeirinha, a imagem de choque consiste, igualmente, em uma fenomenologia do encontro entre a polícia e os rapazes. A estética marcada pela inscrição do abrupto e por uma materialidade que realça o encontro agressivo da câmera com o real - especialmente da intervenção do acontecimento violento sobre a câmera e o corpo que a segura. O caos visual, índice da movimentação de um celularcâmera que se mexe e desaba junto com o corpo. Até mesmo o quadro estabilizado por mais de sete minutos: tudo isso é forma, sensação e também informação sobre as condições de captação, sobre ação e reação, sobre movimentação destes corpos no espaço. Mesmo os instantes mais obscuros e abstratos, aparentemente vazios de dados documentais, que poderiam ser tomados por certos espectadores como pura forma, carregam uma dimensão epistemológica.

A cena predominantemente acústica e abstrata no plano visual, sem os limites e a organização espacial propiciada pela imagem, traz um ordenamento insuficiente dos elementos de maneira a propiciar a visão do fato. Tampouco articula devidamente a violência em palavras: nenhum morador ou vítima diz diretamente o que aconteceu, as falas são todas laterais, desviantes e comedidas - embora o ódio calado, não expresso, paire o tempo todo, depois de revelado na curta explosão da moradora a gritar palavrões no início do vídeo, que na imagem funciona como um lapso (o ato efetivo de revolta virá no dia seguinte, com a queima de ônibus como protesto pelo assassinato de Alan, também documentada em vídeo). Um vídeo "bruto" e com o estatuto de matéria-prima, parece inacabado também em virtude da inaptidão de trazer a verdade profunda à ordem do visível e da linguagem verbal, de maneira direta e explícita. 
Portanto, a singularidade deste vídeo na comparação com outras filmagens amadoras de evidência é a conjugação de efeitos documentais e figurativos, o que o torna especialmente complexo - e com efeitos diversos de outras imagens "cruas". Menos do que mostrar a própria coisa, este vídeo alude, sugere; estimula a imaginação. Assisti-lo torna-se uma experiência sobretudo mental. Embora o realismo intensificado e a marcação, no nível discursivo, de que se trata de um registro factual do mundo histórico, os fatos, os corpos existem para o espectador apenas mentalmente.

Essa imagem tem também um excesso da ordem do não-dito. Não é só o corpo, o ato violento. Há toda uma reação posterior vazia de respostas, de arroubos, cheia de intimidação, um grito preso que se revela nas falas, na ausência de uma atitude - ora, os feridos demoram para ser socorridos. As imagens digitais que circulam convocam a uma reação - muitas vezes, passiva, mais voltada ao consumo e a uma participação anódina. Neste caso, a reação é outra: trata-se de uma imagem sobre a qual é preciso falar; dá uma compulsão de preencher esses vazios com palavras, descrições.

É uma imagem cuja visualização incomoda e cujos apelos remetem ao sensacionalismo. Por isso, talvez não devesse circular. No entanto, flagra mais um caso de crime policial na periferia, que terminaria acobertado. Mais: é reveladora, assim como outros vídeos de evidência a circular sobretudo através da web, da repetição dessa violência histórica que só agora começa a ganhar visibilidade efetiva nos grandes veículos de mídia. 


\section{Referências}

CAPRIGLIONE, L. "Os mecanismos midiáticos que livram a cara dos crimes das polícias militares do Brasil". In: KEHL, M. R.; DUNKER, C.; et al. Bala perdida: a violência policial no Brasil e os desafios para sua superação. São Paulo: Boitempo, 2015.

CHION, M. Audiovisão: som e imagem no cinema. Lisboa: Texto e Grafia, 2008.

DIDI-HUBERMAN, G. Imagens apesar de tudo. Lisboa: KKYM, 2012.

submetido em: 19 mar. 2016 | aprovado em: 04 mai. 2016 